\title{
¿Locos o simplemente excéntricos? Observaciones acerca de la figura del loco en la literatura alemana a partir de su relación con el personaje de don Quijote
}

\author{
ISABEL HERNÁNDEZ*
}

¿Qué literatura europea no cuenta en su haber con un personaje que pueda describirse como un individuo "que se comporta de un modo inhabitual, extraordinario, poco común o frecuente, extravagante [de genio o de comportamiento] y propenso a singularizarse" ? Un comportamiento inhabitual y una propensión a la singularización son características por las que se definen en buena medida los personajes más conocidos de la literatura europea: bien sea Till Eulenspiegel o don Quijote, todos dan testimonio de una forma de vivir y de pensar que se aparta en mucho de las actitudes de los individuos "normales". Ya desde sus comienzos la literatura definió con claridad la figura del loco, pero no sería hasta finales del siglo XVIII cuando aparecería en la escena literaria una nueva denominación, la del "tipo original, excéntrico, raro", una figura

*. Universidad Complutense de Madrid.

1. DRAE, s.v. raro. El término "extravagante" también podría aplicarse a algunos de estos personajes en el sentido en que se trata de individuos "raros, extraños, desacostumbrados, excesivamente peculiares u originales", tal como los define el DRAE. Por otro lado, la definición que el diccionario alemán da para Sonderling, el equivalente de lo que en español denominaríamos como un tipo raro, extravagante o excéntrico ("de carácter raro, extravagante" según el DRAE), se ajusta muy bien al tipo de personaje que se analizará aquí: "Mensch, der sich in Urteil, Meinung, Geschmack, Lebenshaltung in wunderlicher, Lächeln oder gar Spott erregender Weise von den Mitlebenden absondert" ["individuo que se diferencia del resto de sus congéneres en juicios, opiniones, gustos y formas de vida, de manera extraña, provocando risa o incluso burla"]. Grimms Wörterbuch, s.v. Sonderling. 
que, evidentemente, aúna en sí las cualidades antes mencionadas. La tardía fijación de este tipo literario se corresponde de manera evidente con la necesidad de crear una nueva denominación literaria para un nuevo individuo que en esa etapa preburguesa difícilmente podía ser calificado de loco, pero que, a su manera, presenta diversas cualidades propias de una forma de comportamiento "anormal", dado que rechaza de plano una adaptación impuesta, sea de la manera que sea, a los condicionamientos de la sociedad. No obstante, si este personaje hace su aparición tan tarde en la escena literaria, lo cierto es que sus antecedentes llegan hasta muy atrás, puesto que su origen se encuentra evidentemente en la literatura de carácter didáctico y satírico de los siglos XVI y XVII, un ámbito del que esta figura del personaje excéntrico se va desprendiendo poco a poco para convertirse en un personaje independiente, redondo, cerrado en sí mismo.

A cualquier buen lector que tenga ante sí la descripción de uno de estos personajes tan abundantes en la literatura del siglo XIX le resultará evidente que el antecedente más inmediato de este tipo es el loco de la literatura medieval. El loco y él tienen en común el hecho de que ambos están concebidos como desviación de una norma determinada. La literatura alemana, que cuenta con un género propio en el que el loco es protagonista (la denominada Narrenliteratur o "literatura de locos"), deja ver desde el primer momento un nexo claro entre sinrazón y falta de adaptación social, pero en la época en que el género llegó a su plenitud, el loco es simplemente una personificación alegórica de determinadas cualidades humanas, sin ningún tipo de individualidad, como se puede observar por ejemplo en Das Narrenschiff ( $\mathrm{La}$ nave de los locos, 1494) de Sebastian Brant o en Die Narrenbeschwörung (La conjura de los locos, 1512) de Thomas Murner ${ }^{2}$. Tan sólo con la publicación del anónimo Till Eulenspiegel (1515) comienza a constatarse ya una primera adaptación al ámbito de lo terrenal del concepto de loco, pues hasta entonces este personaje era visto única y exclusivamente en su relación frente a Dios o, lo que es lo mismo, en relación a los contrarios universales del bien y el mal. Precisamente el mal, sin dejar espacio alguno a la presencia del bien, es la cualidad que define a Eulenspiegel como tipo literario frente a otros posteriores de su misma especie. Los estudios sobre el personaje abundan en afirmaciones respecto de que Eulenspiegel es en realidad un precedente del tipo del pícaro, pero entre los pícaros españoles, según los cuales se define también el tipo en la literatura alemana, puede distinguirse perfectamente una clara dicotomía entre el bien y el mal, que todos los perso-

${ }^{2}$ Das Narrenschiff fue el poema didáctico de carácter satírico-moral más difundido de su época; contiene sátiras acerca de diferentes peculiaridades humanas, así como de formas de comportamiento propias de los diversos estamentos sociales y de las modas de la época. El autor pone todas estas ,,peculiaridades“ juntas en un barco en dirección a „Narragonia“ (el país de la locura), lo que le da la oportunidad de describir ampliamente cada una de ellas. El franciscano alsaciano Thomas Murner fijó por escrito en su Narrenbeschwörung los temas que trataba en sus sermones, criticando los vicios humanos en un tono tremendamente descarnado. 
najes tienen en consideración en cada una de sus actuaciones; por el contrario, tales reflexiones no se encuentran nunca en Till, por lo que resulta imposible poder incluirlo dentro del tipo del pícaro, aun cuando comparta con él numerosas características.

Y es que la novela picaresca, tal como se desarrolló en España, no es simplemente una descripción de tretas, engaños y bromas más o menos ocurrentes al estilo del Till Eulenspiegel. Evidentemente sigue quedando en sus personajes protagonistas algo de la locura medival, pero simplemente como una máscara que un pobre joven, expulsado del orden social, tiene que ponerse de vez en cuando para poder abrirse camino en la vida, tal como hacen todos los pícaros de una u otra manera. En la sociedad estamental española el pícaro está marcado por una serie de valores que giran en torno a los conceptos de honor y vergüenza. Pero hay que conocer muy a fondo estos valores y su función en la vieja cultura estamental para comprender lo que significan en realidad: el honor -tal vez sería mejor decir "la limpieza de sangre" - es el motor que impulsa al pícaro a ponerse en movimiento, o, dicho de otra forma, los tipos que, en parte, pueden denominarse como picarescos han nacido en medio de la ignominia, la cual les impulsa a actuar debido a la apremiante necesidad de librarse de ella ${ }^{3}$. Es justamente esta perspectiva la que permite al lector reconocer la situación social anacrónica que pone al descubierto la novela picaresca, pues precisamente desde la perspectiva del pícaro se desenmascara y se muestra con toda claridad el juego existente entre apariencia y realidad. Un conocido ejemplo explica esto a la perfección: el escudero -hidalgo venido a menosmanda al protagonista, Lázaro, a mendigar para él, pero de cara a la sociedad no quiere mostrar a nadie su pobreza, escarbándose los dientes con una brizna de paja como si acabara de comer, para, de ese modo, mantener su honor ante sus conciudadanos ${ }^{4}$. El pícaro, por el contrario, tiene un carácter inquebrantable, pues se ve expuesto a un mundo plagado de tentaciones, a las que no sucumbe sencillamente porque incluso a la vista de su triste situación jamás pierde el optimismo, un optimismo subjetivo que, enmarcado en el pesimismo objetivo de su situación real, se extiende para él a toda la sociedad. Pero lo que no deja de llamar la atención es que precisamente este optimismo es el que hace que no pueda vivir en ella: su especial ingenio le sirve en estas circunstancias de gran ayuda, cualidad ésta que todo pícaro posee, puesto que la movilidad física y la capacidad de improvisación

3. En este sentido, respecto de los pícaros alemanes véase mi artículo „Nuevos tiempos, nuevos héroes: el ciclo picaresco de Gerold Späth“, Tradición e innovación en los estudios de lengua, literatura y cultura alemanas en España, Grupo de InVEStigación Filología Alemana (eds.), Sevilla, Kronos, 1998, 143-151.

4. Cfr. La vida de Lazarillo de Tormes y de sus fortunas y adversidades, Madrid, Castalia, 1972, 144: „Y por lo que toca a su negra, que dicen, honra, tomaba una paja, de las que aun asaz no había en casa, y salía a la puerta escarbando los dientes que nada entre sí tenían, quejándose todavía de aquel mal solar, $[\ldots]^{6}$. 
en situaciones siempre diferentes, que cambian a toda velocidad, son condiciones sine qua non para poder sobrevivir en esa sociedad atrasada que no lo tiene en cuenta para nada. En general, no obstante, sus artes en este campo se limitan a trucos corrientes, sin ningún ánimo de maldad, para los que se necesita simplemente tener mucha imaginación -io también mucha hambre!-.

Mientras la literatura española deja ver ya con claridad los cauces por los que se moverán esta clase de personajes literarios, en la alemana el concepto de "loco" se mantiene durante todo el periodo del Barroco sin grandes alteraciones, tal como puede observarse, por ejemplo, en la novela de Christian Weise Die drei ärgsten Erznarren in der ganzen Welt (Los tres peores locos del mundo, 1672). Aquí, no obstante, al contrario que en Eulenspiegel o en los pícaros españoles, los locos son otra vez alegorías del comportamiento humano, en tanto que personifican diferentes cualidades humanas, pero sin definirse por su relación con la dicotomía existente entre el bien y el mal. Un breve resumen del contenido resulta necesario para comprender la nueva concepción del tipo: un joven noble hereda un imponente castillo; no obstante, el testamento tiene una cláusula que dice que, antes de heredarlo, tendrá que pintar en una de sus salas a los tres mayores locos del orbe terrenal, tras haberlos encontrado en persona. Para ello tendrá que viajar por el mundo y verlo bien. La intención pedagógica de la cláusula resulta evidente: los locos que el joven se encuentra en su camino son la viva personificación de todos los defectos y los vicios humanos. Tras haber concluido el viaje, sin embargo, será un grupo de sabios el encargado de dar respuesta a la pregunta de cuál es el mayor de los locos, para lo cual expondrán su propia definición de la locura en forma de silogismo: la locura no es otra cosa que la falta de cordura, de ahí que todo aquel que sea capaz de reconocer la cordura no tendrá dificultades en deducir de lo contrario quién es un loco.

Completamente diferente, sin embargo, es la actitud de una de las figuras más famosas de la literatura alemana: Simplicius Simplicissimus (1669) de J.J. Ch. von Grimmelshausen. Su visión es totalmente opuesta a la de Weise, puesto que el concepto de locura tiene una definición completamente diferente en ambos textos: para Weise la locura es tan sólo una carencia de la que uno puede librarse si se tiene una clara visión de la esencia de la cordura; la concepción de Grimmelshausen, en cambio, radica en algo muy diferente, en la vanitas, pues todo lo terrenal no es para él-como para la época en general en la que escribe- más que pura vanidad. Las correrías de Simplicius aparecen, pues, a la luz de una locura universal que poco o nada tiene que ver con la de Eulenspiegel, pues el personaje no es un medio para cumplir una finalidad didáctica o satírica determinada: su importancia radica única y exclusivamente en su forma de actuar individual y alegórica. Pero esta afirmación parece contradecirla el hecho de que el Simplicissimus es una novela en la que la acción no viene determinada por la evolución interna del protagonista, sino por los avatares de la vida. Aun con todo, es precisamente en esa relación entre hombre y mundo donde se hace visible el germen de esa imagen del hombre. Her- 
mann Meyer lo ha definido de la siguiente manera en su conocido estudio sobre el tema en la literatura alemana:

Es gehört zum Wesen des reinen Toren, dass er in eine Welt gerät, die ihm als Irrgarten erscheint, oder die ihn der Gefahr aussetzt, sich in Sünde zu verstricken und im Schmutz der Welt unterzugehen. Das Bild des Menschenlebens ist nicht kontinuierliche Entwicklung sondern unbeständiges Hin- und Hergeworfenwerden; das Bild der Welt nicht konstanter Hintergrund der persönlichen Entwicklung sondern auf den Menschen losstürmendes Abenteuer, Unbeständigkeit. Simplicissimus erfährt, 'dass nichts beständigers in der Welt ist als die Unbeständigkeit selbsten'. Neben der Vanitas erscheint ein zweites klassisches Sinnbild, das unbeständige Glück, die rollende Kugel der Fortuna als Ausdruck dieses Weltbildes ${ }^{5}$.

La evolución posterior del tipo está en estrecha relación con la influencia del protagonista de la gran novela de Miguel de Cervantes Don Quijote de la Mancha (1605-1615). Para comprender el momento en que se escribe esta obra basta con señalar que las novelas picarescas más famosas se acumulan en un periodo no superior a treinta años, y que el Quijote está justo en la mitad de ese periodo ${ }^{6}$. En ella, la crítica a los libros de caballerías está en relación directa con un proceso de transformación social en el que todo el mundo de los pícaros adquiere un nuevo significado frente a las clases sociales más altas, ahora en proceso de desaparición. Lo novedoso de esta novela incomparable está precisamente en que aquí, al contrario que en la literatura satírica alemana, aparece por vez primera una figura con marcados rasgos individuales, una aparición que será de gran importancia, puesto que la posterior evolución del tipo arrancará precisamente de ahí. A causa de esta individualidad, como también de su aislamiento del mundo, sería posible calificar a don Quijote sencillamente de excéntrico, de raro; no obstante, resulta evidente que está aún emparentado con el tipo del loco, en tanto que es un medio para cumplir una finalidad pragmática, de ahí que la genialidad del autor radique sin más en el hecho de que este personaje está concebido a partir de un motivo absolutamente nuevo e inauditamente fructífero, esto es, a partir de la discrepancia insalvable que surge de la dicotomía existente entre la realidad objetiva y la fantasía subjetiva del protagonista.

5. „Es parte de la esencia del loco puro que entre en un mundo que a él le parece un laberinto, o que lo expone al peligro de enredarse en el pecado y perecer en la inmundicia del mundo. La imagen de la vida humana no es un desarrollo continuado, sino que el individuo es arrojado continuamente de un lado para otro; la imagen del mundo no es el trasfondo constante de la evolución personal, sino una aventura que se abalanza sobre el hombre, inconstancia. Simplicissimus aprende ,que no hay nada más constante en el mundo que la inconstancia misma'. Junto a la vanitas aparece otro símbolo clásico, la inconstancia de la fortuna, la rueda de la fortuna como expresión de esa concepción del mundo“. MeYer, Hermann, Der Sonderling in der deutschen Dichtung, Frankfurt, Fischer, 1984, 29-30.

6. Téngase en cuenta, por ejemplo, que el Guzmán de Alfarache de Mateo Alemán, que dio el nombre al género de la novela picaresca, se publicó entre 1599 y 1605, el Marcos de Obregón de Espinel en 1618, y el Buscón de Quevedo en 1626; tan sólo el Lazarillo de Tormes se publicó por vez primera en 1554. 
Don Quijote, que está completamente perdido en su mundo y en sus ensoñaciones, ha traspasado el umbral de la razón a consecuencia de mucho leer y poco dormir. Es víctima de una fantasía que ha cobrado forma en su cerebro y, aunque sabe que la ilusión es engañosa, está convencido de que todo lo que haga en su defensa merece la pena. De ahí que no confíe más en la realidad y que evite que todo lo real, que los hechos, le demuestren en ningún momento lo contrario de lo que él piensa. Precisamente por ello don Quijote pertenece a esas figuras de la literatura que despiertan siempre el interés estético y humano, y que requieren múltiples interpretaciones, al tiempo que resulta muy probable que Cervantes tratara de plasmar en su novela una crítica del idealismo personificada en la figura de un pobre caballero, y parodiada por la razón objetiva en la figura de su fiel servidor Sancho Panza: pero justo en este sentido podría afirmarse que el libro es la mayor sátira jamás escrita contra el entusiasmo humano, contra la posibilidad de transformar el mundo, de verlo de manera diferente a como en realidad es; no obstante, no deja de ser por ello tampoco una sátira contra el realismo, porque Sancho, con su clarividencia, con todos sus útiles refranes campesinos y a pesar de su sano juicio, no sabe hacer otra cosa más que cabalgar tras el loco caballero y compartir con él todas sus aventuras. Importante es, en cualquier caso, el hecho de que don Quijote no sabe emplear su idealismo para un fin razonable, sino que imita ciegamente a los protagonistas de sus libros de caballería, pues en su forma de pensar sigue siendo un hombre medieval que cree tan ciegamente en las historias de estos personajes como el hombre de la Edad Media en los dogmas de la Iglesia.

Con todo, no deja de resultar interesante que la psicología moderna no vea un loco en el caballero de la triste figura, sino la imagen clásica del denominado "tipo esquizoide": alto, seco, enjuto, pálido e insomne, la personificación de un idealismo ajeno al mundo y de un rigorismo excesivamente ético que simplemente no comprende nada de lo que ve a su alrededor y ha de hacerlo todo como él piensa que es correcto. Para ello el autor habría seguido modelos vivos y habría descrito a un tipo de enfermo real, con lo cual la actitud del protagonista habría que interpretarla como causa de una enfermedad mental que en aquellos tiempos sencillamente se denominaba como "locura"7. Por el contrario, Sancho sería la personificación del tipo opuesto: gordo, comodón, realista, algo limitado y práctico, capaz de sacar provecho a todo. Ambos, no obstante, se complemetan a la vez que se parodian a la perfección, y ello aunque la pareja don Quijote - Sancho se concibe siempre como una pareja antagónica, de manera que los rasgos que los caracterizan se transforman en dos grupos de valores, pues de don Quijote siempre se espera valentía, fe, idealis-

7. El concepto de „locura“ ha sido estudiado tal vez con excesiva frecuencia. No obstante, en su artículo mencionado en la bibliografía „On the place of madness, deviance and eccentricity in Don Quijote“, Hispanic Revuew 70, 2002, 1-23, David A. Boruchoff lo analiza desde la época clásica dando unas claves muy interesantes de cómo evolucionó hasta llegar al siglo XVI. Vid. especialmente las páginas 2-12. 
mo, utopía y pensamiento liberal, mientras que de Sancho tan sólo cobardía, escepticismo, realismo y sentido práctico.

Entre los presupuestos necesarios para la construcción del protagonista no hay que olvidar los históricos, los culturales y los sociológicos. El caballero andante tiene modelos ya desde antaño en el ámbito de las culturas mediterráneas, pues se trata en realidad de una tergiversación literaria ${ }^{8}$ (a este respecto no debe olvidarse que el escapismo hacia formas de vida más primitivas fue un modelo de comportamiento social muy del gusto de las capas altas de la so$\operatorname{ciedad}^{9}$ ), pues en todos los tiempos y en todos los lugares ha habido individuos convencidos de poder abandonar su propio ser y transformarse en otro completamente diferente, cosa que precisamente intenta hacer también aquí el autor. En este sentido resulta sumamente artística la forma en que Cervantes funde en su obra los diferentes géneros de la novela picaresca, la novela pastoril y la novela de caballerías: el protagonista es el representante del mundo heroico, de los caballeros, las formas de vida que se describen a lo largo de la novela concuerdan con las formas de vida bucólicas, pastoriles, y el elemento picaresco se percibe en la descripción de los diferentes tipos populares que participan en la acción, así como en la de algunos tips curiosos del ámbito de los marginados, aunque también el personaje de Sancho recuerda en cierto modo al género picaresco. Ya en la primera parte el autor utiliza la colisión que se produce entre el género picaresco y el heroico más bien como un recurso artístico, tal como se ve por ejemplo en la escena donde don Quijote libera a los presos de galeras. Él, que lo que quiere siempre es "enmendar entuertos", esto es, servir a la justicia, se convierte con ello en un criminal. De este modo, una buena parte del efecto cómico que producen las apariciones y las supuestas acciones heroicas del caballero resulta precisamente de una colisión grotesca con el mundo real que, en realidad, no es más que un mundo de pícaros. No obstante, Cervantes añade un elemento más a la caracterización de don Quijote haciendo que la razón de su protagonista no se desvanezca totalmente, ni siquiera cuando éste asume por completo su papel de caballero andante.

Si se analiza, pues, la figura del hidalgo desde el punto de vista de una personalidad mentalmente enferma, puede comprobarse que no es posible suponer nada extraño ni fuera de lo común en ese caballero generoso y bondadoso, aunque algo triste. Pero las apariencias engañan: una ardiente e insaciable fantasía transforma en su cabeza las aventuras más ridículas en pura realidad.

8. Estas „tergiversaciones literarias“ fueron analizadas por primera vez por André Jolles, quien partiendo de la novela francesa del s. XVII y basándose en ejemplos determinantes definió tres formas principales de tergiversaciones: la heroico-galante del caballero, la bucólica o pastoril del pastor y la picaresca del pícaro. En estas tres formas literarias se aspira a tres formas de vida diferentes, pero lo interesante desde el punto de vista sociológico es, sin duda, que en los siglos XVII y XVIII hubo unas determinadas clases sociales que buscaron la entrada en uno de estos géneros en el marco de su vida cotidiana. Cfr. Jolles, André, „Die literarischen Travestien. Ritter, Hirt, Schelm“, Bulletin für deutsche Philosophie, 6, 1932, 281-294.

9. Piénsese sobre todo en la época barroca, en la que las clases altas gustaban de disfrazarse de pastores e imitar sus formas de vida. 
Todos los que lo conocen, dan fe de que él, con excepción del hecho de que se cree un caballero andante, es el hombre más razonable y sobrio que uno pueda imaginarse; incluso el cura da testimonio de su sano juicio. No obstante, tan pronto como se decide a salir en busca de aventuras, pierde completamente el juicio. La esencia de lo que resulta de la fijación de ideas no podría haberse descrito de manera más certera, pues la actividad que despliega cuando ha de transformar en hechos reales la esencia y finalidad de la caballería, despierta el asombro de todos los que lo rodean. De ahí que resulte difícil no creer en su palabra cuando, por ejemplo, dice al barbero:

Yo, señor barbero, no soy Neptuno, el dios de las aguas, ni procuro que nadie me tenga por discreto no lo siendo; sólo me fatigo por dar a entender al mundo en el error en que está en no renovar en sí el felicísimo tiempo donde campeaba la orden de la andante caballería. ${ }^{10}$

Por otro lado resulta inevitable no ver en don Quijote las reminiscencias de una forma de pensar arcaica, primitiva. Su fe en la autoridad se corresponde con ello, pues en todo lo que hace apela siempre a lo que ha leído en sus libros de caballerías, de tal forma que, en lo que respecta a esa fe ciega en las letras sigue siendo aún, por tanto, un hombre medieval, puesto que su forma de pensar no se ha liberado aún del peso de las antiguas ideas. Su intelecto, que no ha madurado todavía, sale en busca de aventuras sin haberse ejercitado antes, de la misma manera que toma al pie de la letra todo lo que ha leído en sus libros acerca de Amadís de Gaula, Fierabrás, los caballeros de la Tabla Redonda, etc., y defiende estos conocimientos "históricos" ante cualquiera que dude de ellos con tal aplicación que resulta difícil contenerlo. Pero la presentación del caballero no estaría completa sin el personaje sin par de Dulcinea del Toboso, pues a sus cincuenta años decide de repente que para poder ser caballero andante ha de estar además, tal como ha leído en sus libros, necesariamente enamorado. Así pues, también él ha de buscarse una dama, y el recuerdo de la joven Aldonza Lorenzo, una moza campesina del vecino pueblo de El Toboso, le lleva a coronarla como su amada. Que la idolotrada moza no es en absoluto la belleza con la que él sueña y que describe a los que le rodean como real, es otra buena muestra de la dicotomía entre el ser y el parecer que domina toda la novela.

Sancho Panza, el campesino al que don Quijote nombra su escudero, es el otro personaje de la novela y merecería un análisis aparte, igual que el protagonista. Pues la ironía de la obra radica precisamente en la tremenda distancia que hay entre el caballero y su escudero. El autor enfrenta al caballero loco con Sancho Panza, el representante de la objetividad; cierto que a veces éste se pierde también en el mundo de la locura de su señor, pero precisamente de esa forma es como el autor enfrenta de manera mucho más directa el realismo tosco de Sancho con la fantasía del supuesto caballero. Allí donde Cervantes 
lleva a cabo un juego enormemente irónico con la antítesis entre el ser y el parecer, para don Quijote no es en absoluto un juego, sino algo muy serio. Con similar distanciamiento irónico maneja el autor también el motivo de la locura. Don Quijote no es sólo un loco, sino que le parece incluso adecuado "hacer locuras", porque lo hace imitando las andanzas, convertidas ya en motivos literarios, de los caballeros medievales. Es decir, que la novela, y con ella también la figura de este excéntrico personaje está marcada de principio a fin por la lucha entre el ser y el parecer: la figura de don Quijote no aparece determinada por el carácter, sino por su trasfondo psicológico, de ahí que no se pueda rastrear ninguna huella de la evolución de su personalidad. Esto se hace especialmente evidente al final de la novela, cuando don Quijote se percata de su locura, maldice los libros de caballería y alaba a Dios que le ha devuelto a su sano juicio.

El análisis de la novela bajo estas premisas permite ver que el texto ofrece dos niveles diferentes de lectura: la confirmación de la realidad, por un lado, si el lector es capaz de ver sin más las fantasías del protagonista, y la entrada en una forma de actuar contraria a la realidad, por otro, si se viven esas aventuras junto con el protagonista ${ }^{11}$. Puesto que, bajo la presuposición de realidad se presenta la irrealidad como paradigma, ese mundo irreal y mejor tiene que aparecer como un mundo equivocado e inventarse como un mundo lleno de ocurrencias, ya que tan sólo en la imaginación poética pueden saltarse las barreras de la realidad insondable. Por eso el autor se convierte así en una instancia capaz de decirle la verdad al mundo real y hacer que, a través de su mundo inventado, se perciban las carencias de aquél, tal como ocurría también en la novela picaresca.

Heredero directo de don Quijote en la literatura alemana es el protagonista de la novela de Christoph Martin Wieland Die Abenteuer des Don Sylvio von Rosalva (Las aventuras de Don Sylvio von Rosalva, 1762-1763). Don Sylvio es un joven noble español que ha sido educado por una anciana tía lejos del mundo, en la soledad del campo, para convertirse en el noble ideal, perfecto (¿quién no recuerda aquí a uno de los personajes más famosos de la literatura alemana medieval, el joven caballero Parzival, considerado también como un individuo sumamente excéntrico y peculiar?). Pero la tía tan sólo sabe qué cualidades ha de tener un noble tal por los libros de caballerías, que conforman la práctica totalidad de su biblioteca. Y, ciertamente, el joven se siente tan atraído por las novelas que arde en deseos de actuar igual que sus sublimes modelos. La influencia del Quijote es evidente desde el primer momento, pero Wieland trata de superar aquí a su modelo, profundizando mucho más en la motivación psicológica del protagonista, de manera que el lector pueda llegar a comprender el porqué del carácter fantasioso del joven: la na-

11. Cfr. en este sentido JAUSs, Hans Robert (ed.), Nachahmung und Illusion, Múnich, Fink, 1964, en especial el capítulo de Hans Blumenberg titulado „Wirklichkeitsbegriff und Möglichkeit des Romans", pp. 9-27. 
turaleza lo ha dotado de una enorme sensibilidad y de una tremenda ternura. Estas cualidades innatas adquieren en él doble fuerza, debido a su ingenua educación en la soledad del campo, en tanto que su imaginación ha tenido que sustituir su falta de experiencia en todos los ámbitos de la realidad cotidiana. También, y al igual que en Cervantes, la imaginación es valorada aquí como algo equivocado, negativo, de lo que no se precisa en absoluto para vivir en el marco de la objetividad de la sociedad.

Poco tiempo después caen en manos del joven, tan predispuesto a la fantasía, los cuentos de hadas orientales que su tía desprecia. Los considera como la más pura verdad y trata de hacer realidad esas fantasías. En sueños se enamora de una princesa de cuento que ha sido transformada en mariposa por un duende malvado y a la que quiere devolver a su forma primitiva. Para este fin, $\mathrm{y}$ al igual que don Quijote, se dispone a ir en busca de aventuras, "a la caza de hadas" como lo denomina su fiel servidor Pedrillo, una variante muy conseguida de Sancho Panza. Un retrato en miniatura que el joven se encuentra, y en el que el hada aparece en su figura original, constituye el nexo de unión entre su mundo de fantasía y el mundo real, pues se trata en realidad del retrato de doña Felicia, la cual ve por vez primera a Don Sylvio cuando éste está durmiendo en el bosque, se enamora de él y se propone conquistar al bello durmiente para quitarle de la cabeza todas sus fantasías. Precisamente esto es lo que diferencia a don Sylvio de don Quijote: su desvinculación del mundo de los cuentos tiene lugar progresivamente por medio de una refinada intriga psicológica. Por un lado es el amor por Felicia el que le hace volver a tener sentimientos humanos; pero por otro también el triunfo de la razón, personificada en su contrincante, el tío de su amada. Si el mundo de don Quijote está construido a partir de la dicotomía existente entre fantasía y realidad, el de Don Sylvio se apoya sobre la base de un tercer elemento, el de los sentimientos: tan sólo superando su fantasía y gracias al amor podrá tener los sentimientos más puros hacia una dama. De este modo consigue superar sus excentricidades, experimentando un giro hacia un tipo de intimismo, que, evidentemente, es paradigmático en el periodo del Sentimentalismo ${ }^{12}$.

La influencia de don Quijote no se limita exclusivamente a suelo alemán, sino que se extiende por toda Europa. Entre los modelos por excelencia que resultan imprescindibles para comprender el desarrollo de este tipo literario, no es posible pasar por alto la literatura inglesa, en la cual el proceso de evolución de la literatura satírica y didáctica presenta rasgos similares a los de la literatura alemana, aunque tenga lugar de una manera mucho más radical, puesto que la novela inglesa alcanzó mucho antes que la alemana un nivel desde el que influyó de manera decisiva en la configuración de la prosa en el resto de las literaturas europeas. Dos obras dan testimonio de ello: The Life and Opinions of Tristram Shandy, Gentleman (1767) de Laurence Sterne y The 
History of the Adventures of Joseph Andrews and his Friend Mr. Abraham Adams (1742) de Henry Fielding ${ }^{13}$. En su novela, Sterne renuncia a una estructura externa objetiva, de manera que el protagonista, o lo que es lo mismo, el individuo, pasa a primer plano del interés. A partir de este momento, todos los personajes de características similares a las ya definidas aparecerán presentados como tipos justificados en sí mismos. Sterne lo consigue aquí por primera vez gracias al uso continuado del humor, que hace que el lector tenga que concentrarse necesariamente en los personajes sin que haya de prestar excesiva atención a la forma. Los protagonistas de la novela son, en realidad, el padre de Tristram y su tío Toby; el personaje de Tristram en sí permanece siempre en el fondo haciendo las veces de narrador. En la novela se retoma de forma muy evidente el motivo de don Quijote: el padre y el tío son, en realidad, dos individuos sumamente excéntricos, puesto que tienen una relación totalmente alterada con el mundo que los rodea, aunque las disposiciones mentales sean diferentes en ambos $\operatorname{casos}^{14}$. El padre es un teórico puro que de forma monomaníaca colecciona y lee todos los libros y tratados que se hayan escrito jamás acerca de la nariz; esto se explica por el hecho de que en la familia Shandy existe desde antiguo la convicción de que con vistas al matrimonio resulta muy desventajoso tener la nariz chata, dado que esto tiene como consecuencia inmediata tener que aportar una elevada dote (!). Esto a su vez lo lleva a convertirse en un fanático de las palabras: la palabra es para él, incluso como mera forma, un ser independiente, que ejerce una determinada influencia, a menudo perjudicial, sobre el hombre. En este sentido cree firmemente en que el nombre de pila influye en la personalidad de quien lo lleva, de ahí que para el bautizo de su hijo él haga todos los preparativos necesarios

13. En su artículo „Don Quijote-Figuren als unzeitgemässe Helden in der englischen Literatur“ Wolfgang G. Müller pasa revista a todos los herederos ingleses de Don Quijote. Véase además PARDO GARCíA, Pedro Javier, „Formas de imitación del «Quijote» en la novela inglesa del siglo XVIII: «Joseph Andrews» y «Tristam Shandy»“, Anales cervantinos XXXIII, 1995, 133-164, que contiene un apéndice bibliográfico muy amplio al respecto.

14. A lo largo de toda la novela son muy numerosas las alusiones directas al personaje de Don Quijote: „I know very well that the HERO's horse was a horse of chaste deportment, which may have given grounds for a contrary opinion: But it is as certain at the same time, that Rosinante's continency (as may be demonstrated from the adventure of the Yanguesian carriers) proceeded from no bodily defect or cause whatsoever, but from the temperance and orderly current of his blood." "The Hero of Cervantes argued not the point with more seriousness, _ nor had he more faith, — _ or more to say on the powers of Necromancy in dishonouring his deeds, _ or on DulcinEA's name, in shedding lustre upon them, than my father had on those of TRISMEGISTUS or ARCHIMEDES, on the one hand, - or of NYKY and SIMKIN on the other." "In the second year my uncle Toby purchased Ramelli and Cataneo, translated from the Italian; _ likewise Stevinus, Marolis, the Chevalier de Ville, Lorini, Coehorn, Sheeter, the Count de Pagan, the Marshal Vauban, Mons. Blondel, with almost as many more books of military architecture, as Don Quixote was found to have of chivalry, when the curate and barber invaded his library". STERne, Laurence, The Life and Opinions of Tristram Shandy, Gentleman, Penguin, Londres, 1997, pp. 17, 43 y 73 respectivamente. En la última cita Sterne se refiere explícitamente al capítulo VI de la primera parte de Don Quijote: , ,[...] y hallaron más de un cuerpo de libros grandes muy bien encuadernados y otros pequeños“. CERvantes, Miguel de, Don Quijote de La Mancha, Castalia, Madrid, 1978, vol. I, 109. 
para que el niño reciba el nombre, biensonante y de positivas influencias, de Trismegistus, pero, debido a un malentendido, el pobre niño recibe el peligroso nombre de Tristram, lo que, evidentemente, hará de él un hombre ridículo, o lo que es lo mismo, un excéntrico, no muy bien visto por el resto de la sociedad. Este hombre teórico, metido en sí mismo fracasa siempre cuando ha de tener contacto con la vida cotidiana, y para todo lo que ocurre en ella busca consuelo o bien en los libros (es el caso, por ejemplo, cuando Tristram se hiere al caérsele encima una ventana) o en las palabras (justo después de enterarse del fallecimiento de su hijo mayor hastía a todos los presentes con un larguísimo y pedante discurso acerca del valor perecedero de todas las cosas terrenales).

El tío Tobias funciona en la novela como un espejo del padre. Convencido de su glorioso pasado como héroe de guerra, así como de la idea de la validez de ésta, guarda en su biblioteca tantos libros sobre las artes defensivas como don Quijote sobre la caballería. Precisamente por ello se olvida también de su entorno, pues, por ejemplo, cuando alguien va a visitarle para ver cómo se encuentra de sus dolores -en el asedio de la ciudad de Namur había resultado herido en la cadera- interesándose por él de manera cordial, Toby siempre le relata en contraprestación, con todo lujo de detalles, la historia de su herida. Pero en este relato, el anciano acaba siempre perdiéndose en descripciones de carácter técnico y estratégico, de manera que al final ni él mismo es capaz de concluir su propia narración. En cualquier caso, vive al margen del mundo, igual que su hermano, en su propio círculo, flotando entre sus libros, del mismo modo que aquél en su glorioso pasado: una forma quizá un tanto más compleja de describir la dicotomía entre ser y parecer, entre fantasía y realidad.

En el caso de Parson Adams, el protagonista de la novela de Fielding, la situación es un poco diferente, aunque la dicotomía entre el ser y el parecer impregna la obra de principio a fin. Parson es tan sólo un soñador bonachón, cuya figura muestra al lector con toda claridad que el mundo está bien ordenado gracias a la sabiduría divina. No obstante, él es consciente de que tiene un lugar en la sociedad y precisamente eso es lo que le diferencia de don Quijote, que no parece saber absolutamente nada del entorno que lo rodea y tampoco de sus estructuras. No obstante, al igual que hiciera Cervantes con su personaje, el autor utiliza intencionadamente el idealismo de Parson para ejercer una dura crítica contra la sociedad.

En la literatura alemana la lista de este tipo de personajes que actúan a la manera de Don Sylvio, es decir, a la manera quijotesca o simpliciana, y más tarde también bajo la influencia de Tristram Shandy, se extiende hasta nuestro siglo. Nombres como Sebaldus Nothanker, Tobias Knaut, Anton Reiser ${ }^{15}$, Siebenkäs, el estudiante Anselmo, el Dr. Katzenberger, Johannes Kreisler, el pin-

15. Sobre la configuración de este personaje en particular y su estrecha relación con el personaje de Don Quijote véase PARADA, Arturo, Offene literarische Welten gegen geschlossene Denkmodelle und Sozialsysteme: Don Quijote und Anton Reiser, Madrid/Frankfurt, Vervuert, 1997. 
tor Nolten, Hans Joggeli, Pankraz, el loco de Manegg o el gobernador del lago de Greifen ${ }^{16}$, entre otros muchos, son suficientes para comprender la magnitud de la influencia de la constitución de un tipo literario como el de don Quijote. En cualquier caso, la fijación de esta línea que lleva directamente desde la literatura de locos de finales de la Edad Media, pasando por don Quijote, hasta este tipo de individuos singulares que pueblan la literatura alemana del siglo XIX, se ve reforzada por el análisis de algunas de las obras del gran realista austriaco Adalbert Stifter. En Die Narrenburg (El castillo de los locos, 1841) Stifter recurre al viejo motivo ya mencionado de la cláusula testamentaria, a través de la cual guía los avatares del protagonista ${ }^{17}$. Siglos atrás un anciano noble, Hanns von Scharnast, había redactado un curioso fideicomiso por el que todos aquellos que heredaran el castillo de Rothenstein debían obligarse a escribir su historia de la manera más completa y fidedigna posible, así como a leer todas las biografías de sus predecesores. El motivo para ello era simplemente que él ,in seinem Leben so viele Narrheiten und Übereilungen begangen, und es war ihm daraus so viel Beschämung und Verdruß zugewachsen, dass er beschloß, alles haarklein aufzuschreiben, ja auch seinen Nachfolgern die Pflicht aufzulegen, dass sie ihr Leben beschrieben, damit sich jeder, der nach ihnen käme, daran zu spiegeln und alle Thorheit zu meiden vermöge, wodurch sich seine Vorgänger etwa in Ungemach gestürzt hatten“18. Es decir, que sus sucesores habían de aprender de ello a actuar de una manera completamente diferente y comportarse de acuerdo con las exigencias de la sociedad. Pero curiosamente con esa cláusula no había obtenido más que el resultado contrario a lo que se proponía, pues ninguno de sus sucesores se había

16. Se trata de los protagonistas de las siguientes obras: Friedrich NiCOLAI, Das Leben und die Meinungen des Herrn Magister Sebaldus Nothanker (1773); Johann Karl WeTZEL, Lebensgeschichte Tobias Knauts, des Weisen, sonst der Stammler genannt (1773); Karl Philipp MoRITZ, Anton Reiser (1785-1790); JEAn Paul, Ehestand, Tod und Hochzeit des Armenadvokaten F. St. Siebenkäs im Reichsmarktflecken Kuhschnappel (1797) y Dr. Katzenbergers Badereise (1808); E.T.A. HoFFMANN, Der goldene Topf (1814) y Lebensansichten des Katers Murr (1819); Eduard MöRIKE, Maler Nolten (1832); Jeremias GotThelf, Hans Joggeli der Erbvetter (1848); Gottfried KelLeR, Pankraz der Schmoller (1846), Der Narr auf der Manegg y Der Landvogt von Greifensee (1877). En el mencionado estudio acerca de este tipo de personajes en la literatura alemana, Herman Meyer establece una tipología diviendo entre personajes excéntricos de carácter cómico, idílico y humorístico. Además ve a este tipo de personajes como exponentes del subjetivismo romántico -como es el caso de E.T.A. Hoffmann, Friedrich Gottlob Wetzel o Joseph von Eichendorff- y también como señalizador del enfrentamiento con el subjetivismo romántico en la literatura del Biedermeier -ése sería el caso de Eduard Mörike, Jeremias Gotthelf y, evidentemente también, de Adalbert Stifter. Vid. MEYER, Herman, op. cit., 62-162.

17. Este motivo aparece con relativa frecuencia en la literatura alemana. Uno de los casos más conocidos es el de la novela de Jean Paul Flegeljahre (La edad del pavo, 1805), en la que la cláusula determina la vida del protagonista hasta el extremo en que sólo gracias a ella llegará a convertirse en un individuo razonable, capaz de amoldarse a su entorno social.

18. ,[...] había cometido en su vida tantas locuras y actuado con tanta precipitación y se sentía tan triste y tan avergonzado, que decidió escribirlo todo con pelos y señales, e imponer a sus sucesores la obligación de que describieran también su vida para que todos los que los siguieran se vieran reflejados en ellas y trataran de evitar una sinrazón como la que había precipitado a sus antecesores a tales adversidades“. STIFTER, Adalbert, Die Narrenburg. En: STIFTER, Adalbert, Sämtliche Erzählungen nach den Erstdrucken, dtv, München, 2005, 412. 
dejado impresionar por las biografías de los otros, sino que simplemente habían actuado según los mismos modelos, de manera que al final habían llegado a cometer tantas locuras que sus biografías rebosaban de ellas ${ }^{19}$.

El linaje de los Scharnast hacía ya tiempo que había desaparecido y del castillo sólo quedaban ruinas en medio de la espesura del bosque. Heinrich, un joven naturalista que desprecia la sociedad, anda explorando por la zona y descubre junto con un amigo el castillo, que el guardés tiene a bien enseñarles. Con el tiempo se descubre que Heinrich es el último descendiente de los Scharnast, y, como nuevo propietario, se decide a reconstruir el castillo. Al leer las biografías de sus antecesores, Heinrich ve con claridad el problema que ha padecido toda su estirpe: todos sufrían de una falta de dominio ante sus propias inclinaciones que los había conducido directamente a su desaparición. Pero Heinrich, a diferencia de ellos, sabe ahora cómo aprovechar todas esas biografías: contrae matrimonio con Anna, la hija del posadero, supera el problema de su herencia genética, así como sus propias inclinaciones, intentando encontrar la armonía, la mesura, esa "mâze" tan apreciada en la Edad Media alemana, en todo aquello que lleva a cabo, aun cuando no consiga superar del todo su pasión por coleccionar plantas exóticas, animales y piedras ${ }^{20}$.

Esta mesura, que se presenta aquí como solución al problema de la locura, es el elemento que rige ya desde el principio la novela más conocida de Stifter: Der Nachsommer (El verano tardio, 1857). Evidentemente se trata de una obra de madurez: si en sus narraciones de los primeros años se veía sobre todo la lucha, ya fuera contra la naturaleza o contra el hombre, que el individuo tenía que vencer para poder actuar como ser independiente, aun cuando la temática siempre se limitara a la victoria o la derrota en esa lucha sin final, Der Nachsommer está impregnada de principio a fin de un constante sentimiento de armonía que puede contemplarse como resumen del conjunto de la producción de Stifter. Todos sus estudios se esfuerzan por dejar constancia con la mayor claridad posible de ese "dulce" estado ${ }^{21}$, en el que el hombre ha de vivir

19. Uno, por ejemplo, había levantado en medio del castillo, un templo similar al Partenón, al que luego él mismo prendería fuego, y en el cual residía con su mujer, una hermosa gitana; otro había instalado un sinfín de catalejos para observar las estrellas, otro no cesaba de tocar un instrumento musical que emitía unos sonidos largos y terribles, otro que buscaba la belleza había llegado hasta el Himalaya, donde había conocido a una bellísima mujer con la que se había casado y llevado luego de vuelta al castillo; otro, por último, había marchado a África para conseguir la fama liberando a todo un poblado oprimido.

20. Resulta curioso que después de enamorarse actúe todavía de una forma mucho más extraña: ,[...] der Naturforscher schien zehnmal närrischer als je, er hieb toll und thöricht in den Gesteinen herum, und trieb alles in fiebrischer Hast und Ungeduld, und schleppte er ganze Bürden von Gesträuchern nach Hause, so warf er am Abends alles in die Pernitz. “ [,... el científico parecía diez veces más loco que nunca, andaba como un poseso de un lado para otro por entre las piedras haciéndolo todo con una prisa y una impaciencia febriles, y si se llevaba a casa a rastras manojos enteros de arbustos, luego, por la noche, lo tiraba todo al Pernitz“.] STIFTER, Adalbert, Die Narrenburg, 449.

21. La obra de Stifter está dominada toda ella por lo que el autor definió como „das sanfte Gesetz“, esto es, ,la dulce ley“ de la naturaleza, según la cual el hombre ha de vivir en armonía con la naturaleza que le rodea si quiere tener una vida feliz y plena. 
en armonía con todo lo que le rodea. De ahí que aparezcan por ejemplo personajes que se ven a sí mismos como excéntricos que son conscientes de sus diferencias, y que, precisamente por ello, tratan de salir de ese estado. Ése es el caso sin ir más lejos del joven protagonista de Der Kondor (El cóndor, 1840): educado en la soledad del bosque es consciente de su carácter soñador y habla a menudo de sus "locos" pensamientos; al principio su vida se rige por esos principios, pues renuncia a toda norma social, dado que repudia las leyes. Pero el amor -igual que en el caso de don Sylvio-, o tal vez mejor dicho el desamor, lo lleva a reflexionar, pues cuando su amada le es infiel se decide a emigrar a Sudamérica e iniciar allí una nueva vida para la que será necesario que supere sus pasiones, así como su tendencia a la soledad. También el protagonista de Die Mappe meines Urgroßvaters (La cartera de mi abuelo, 1841) demuestra una total falta de mesura y unas pasiones no contenidas que lo llevan casi hasta el suicidio. Tan sólo el amor de su único amigo así como el autodominio gracias a la escritura -su amigo le convence para que escriba un diario de su vida- consiguen hacer de él un hombre maduro, acorde con esa "dulce" ley de la naturaleza. El cumplimiento de una obligación se convierte aquí, por tanto, en la vía para llegar hasta el propio yo, en un medio para superar una personalidad marginada, distinta. Aquí, al igual que en Die Narrenburg, el matrimonio aparece además como premio a ese duro proceso de transformación del propio yo. También Der Hagestolz (El solterón, 1846) presenta a otro personaje de estas características como protagonista y que, en realidad, puede muy bien entenderse como reflejo de las relaciones en Der Nachsommer, puesto que aquí se trata también del encuentro entre un joven y un anciano, entre tío y sobrino. Este último, huérfano desde niño, ha sido educado por la bondadosa Ludmilla; pero antes de que se haga cargo de un puesto oficial, habrá de hacer un viaje para visitar a su tío, su único pariente. Éste vive bastante lejos, totalmente retirado del mundo, de manera que al principio no le agrada en absoluto la presencia de su sobrino, llegando a tratarle como si de un prisionero se tratara. Será en el curso de la estancia del joven en el lugar cuando ambos llegarán a conocerse y superen sus mutuas desconfianzas. Siguiendo el consejo de su tío, Victor renuncia a su puesto y emprende un viaje al objeto de conocer el mundo; a su regreso contrae matrimonio con Hanna, la hija de Ludmilla, con la que vivirá el resto de sus días en la hacienda que heredará de su tío. De nuevo es aquí la proximidad de una relación humana, el amor del tío al sobrino, la que saca a un individuo de carácter excéntrico de su aislamiento; pero esta vez, curiosamente, se trata también de otro individuo que vive al margen de la sociedad el que da al joven la llave para la transformación que le hará encontrar el camino adecuado para llevar una vida en el marco del entorno social.

El motivo de esta penosa transformación y del dominio de las pasiones parece no estar presente en Der Nachsommer, pues aquí el lector se enfrenta con personajes que llevan una existencia totalmente equilibrada y tranquila. De ahí precisamente que el barón Risach, en realidad el personaje central de la novela, pueda ser considerado como el ejemplo por excelencia de esa forma de de- 
sarrollo positivo. Pero en realidad se trata una vez más de un individuo de similares características que hace ya mucho tiempo que ha recorrido ese camino de la transformación que luego describirá al joven Heinrich Drendorf con sumo detalle. Su excentricidad consiste principalmente en haber renunciado, tras un amor imposible, a todos los honores de una brillante carrera al servicio del Estado, así como a la vida social, retirándose a sus posesiones donde ha vivido dedicado a sus libros y a su jardín. Esa armonía que reina ahora en su vida la consiguió única y exclusivamente en una durísima lucha consigo mismo. Pero la victoria significó para él dolor, pues tuvo que renunciar a la mujer que amaba y que siempre lo había menospreciado. Sólo en la vejez, tras un matrimonio desgraciado con una mujer a la que no amaba, vuelve a encontrar la felicidad en la amistad tardía, como ese verano que da título a la novela, con la antigua amada. Ahora, en los últimos años de su vida, su dicha es más modesta, pero a cambio más pura que la de aquel amor apasionado de la juventud. Un hombre con tantas cualidades y valores positivos es para Stifter el único capaz de vivir en armonía con la naturaleza para poder desarrollarse en ella. Gracias a esa "dulce ley", el hombre, que, de lo contrario, tiende por lo general a la soledad, puede encontrar un punto de relación con la sociedad y, a partir de ahí, evidentemente, también con el mundo. Para ello, no obstante, se necesita una disposición natural innata al dominio de las pasiones, por un lado, y al libre albedrío, por otro, para poder entrever las normas por las que se rige la sociedad y olvidar así la propia subjetividad personal.

Estos individuos, que, conscientes de su situación, se ven condenados a una vida al margen del ámbito social, se convierten en la sociedad burguesa en individuos que superan de una vez para siempre su subjetividad y son capaces de subordinarse a la objetividad del entorno. Pero esta subordinación no significa en absoluto que el que antaño fuera un individuo de características singulares las pierda para asimilarse a la mediocridad social, sino que sigue siendo el mismo de antes, sólo que capaz de vivir a partir de un momento determinado con la certeza de su dominio interior, así como de una cierta distancia con los individuos comunes. El amor -como también le ocurre a don Quijote con Dulcinea- desempeña un papel extremadamente importante, pues le sirve de ayuda para introducirse en un entorno considerado por él hasta entonces como subjetivo. Por otro lado, en la narrativa realista se hace patente la necesidad de situar a estos personajes dentro de un proceso de formación que persigue como fin último la inserción del individuo en el marco social, para lo cual ha de experimentar un proceso de aprendizaje en el que las experiencias positivas y negativas, el amor y la amistad, ocupan un lugar fundamental ${ }^{22}$.

22. En este sentido véase mi estudio ,'Zurück zur Natur?' La pervivencia del idilio como género literario dentro de la tradición del Realismo europeo. Los modelos de Adalbert Stifter y José Ma de Pereda“, Austria, España y Europa: identidades y diversidades - Österreich, Spanien und Europa: $\mathrm{Zu}$ gehörigkeiten und Abgrenzungen, Maldonado Alemán, Manuel (ed.), Sevilla, Universidad de Sevi1la, 2006, 293-314. 
Así pues, dados estos presupuestos, es posible afirmar que el loco medieval se ha convertido con el paso de los siglos simplemente en un individuo excéntrico, puesto que en la sociedad burguesa no tienen cabida tales existencias extremas, así como tampoco la tienen aquellos individuos que no acatan de forma alguna las normas del entramado social. Esta transformación tiene lugar en un momento en que la sociedad se rige por unas normas aún mucho más estrictas, esto es, en los siglos XVIII y XIX. Pero que estos tipos tardíos, de una manera u otra, presentan aún concomitancias con sus antecesores, es algo que puede reconocerse en determinados rasgos: su tendencia al aislamiento, es decir, a quedarse al margen de la sociedad, su preferencia por la lectura y la escritura (en la constitución de estos tipos es evidente que los libros desempeñan un papel de una importancia sin igual desde que don Quijote enfrentara el mundo de los libros con el mundo real), así como una educación solitaria en la infancia. Todo ello lleva a la imposibilidad de poder diferenciar entre subjetividad y objetividad, esto es, entre fantasía y realidad, algo que, en definitiva, se constituye en la base de su comportamiento y de su aislamiento respecto del mundo. Pero precisamente este hecho es utilizado por los autores para mostrar el mundo tal como es, para poner un espejo ante el lector en el cual puede fácilmente reconocerse, de manera que la función crítica que, en épocas anteriores, desempeñara la figura del loco, es adoptada en el siglo XIX por estos personajes de características excéntricas, extravagantes.

Es evidente, por tanto, que el escritor del siglo XIX posee todos los ingredientes literarios para poder crear una biografía curiosa y peculiar o imitarla simplemente de la realidad y utilizarlo como medio a través del cual ejercer una finalidad clara y concreta. De ahí que la literatura europea del Realismo, que tiende a la descripción de personajes únicos y peculiares inmersos en su vida cotidiana, presente tantas figuras existenciales en las que ya no se puede reconocer a un loco, pero sí a un excéntrico que, al ver el mundo que lo rodea con ojos diferentes, permite construir un pintoresco retrato de una sociedad enormemente peculiar.

\section{REFERENCIAS BIBLIOGRÁFICAS}

AlcAlÁ, Ángel, "Don Quijote como actor o el 'como si' de su locura. Hacia una lectura romántica", Literatura y transgresión, Sierra, Fermín (ed.), Amsterdam, Rodopi, 2004, 55-73.

BoruCHOFF, David A., „On the place of madness, deviance, and eccentricity in Don Quijote”, Hispanic Review 70, 2002, 1-23.

Jauss, Hans Robert (ed.), Nachahmung und Illusion, Múnich, Fink, 1964.

MateJovski, Dirk, Das Motiv des Wahnsinns in der mittelalterlichen Dichtung, Frankfurt, Suhrkamp, 1996.

MatTeS, Josef, Der Wahnsinn im griechischen Mythos und in der Dichtung bis zum Drama des fünften Jahrhunderts, Heidelberg, Winter, 1970.

MAYER, Matthias, Adalbert Stifter. Erzählen als Erkennen, Stuttgart, Reclam, 2001. 
McLean, Benjamin P., „Don Quijote: ¿Héroe o antihéroe?“, Memoria de la palabra, LoBAто, María-Luisa / Domínguez, Francisco (eds.), vol. II, Madrid, Vervuert, 2004, $1317-1328$.

MeYer, Herman, Der Sonderling in der deutschen Dichtung, Frankfurt, Fischer, 1984.

MidELFORT, H.C. Erik, A history of madness in sixteenth-century Germany, Stanford, Stanford University Press, 1999.

MüHLmann, Wilhelm E., Pfade in die Weltliteratur, Königstein /Ts., Athenäum, 1984.

MÜlLENBROCK, Heinz-Joachim, "Don Quijote and the Eighteenth-Century English Literature", Intercultural Encounters - Studies in English Literatures, Antor, Heinz / Cope, Kevin L. (eds.), Heidelberg, Winter, 1999, 197-207.

MüLLER, Wolfgang G., „Don Quijote-Figuren als unzeitgemässe Helden in der englischen Literatur", Der unzeitgemäße Held in der Weltliteratur, Kaiser, Gerhard R., Heidelberg, Winter, 1998, 97-113.

SCHÖNE, Albrecht, Interpretationen zur dichterischen Gestaltung des Wahnsinns in der deutschen Literatur, Tesis doctoral, Universität Münster ,1952.

Simon, Bennet, Razón y locura en la antigua Grecia, Madrid, Akal, 1984.

Titzmann, Michael, „Text und Kryptotext. Zur Interpretation von Stifters Erzählung Die Narrenburg“, Adalbert Stifter. Dichter und Maler, Denkmalpfleger und Schulmann. Neue Zugänge zu seinem Werk, Laufhütte, Hartmut / Möseneder, Karl (eds.), Tübingen, Niemeyer, 1996, 335-373.

WINDSOR, Geoffrey, „Hero, Saint, Eccentric, Victim. Rôle-models in Adalbert Stifter's Bunte Steine", Bristol Austrian Studies, Keith-Smith, Brian (ed.), Bristol, University of Bristol, 1990, 139-158.

\title{
Resumen
}

El presente artículo trata de poner de relieve la estrecha relación que existe entre la figura de Don Quijote y la de los personajes excéntricos o marginados de la literatura alemana de los siglos XVIII y XIX. Partiendo de un análisis del concepto de "loco" en algunos textos de la tardía Edad Media y el Barroco es posible ver la transformación que sufre esta idea a partir de la publicación de la novela de Cervantes y de los pertinentes cambios sociales, así como definir su importancia para las letras alemanas, haciendo hincapié en cómo en ello influyó también de manera decisiva la obra cervantina.

Palabras clave: literatura de locos - concepto de locura - Till Eulenspiegel - Don Quijote - realismo - literatura alemana.

\begin{abstract}
This article intends to call attention to the close relationship which exists between the figure of Don Quixote and the marginal characters and assorted weirdoes who appear in German literature during the 18th and 19th centuries. The analysis of the concept of madness in several texts from the late Middle Ages and the Baroque will enable us, on the one hand, to see how the publication of Cervantes' novel and the consequent changes in society transformed this concept; and, on the other hand, to determine the importance of the idea of insanity for German letters, stressing the decisive role played by Don Quixote therein.
\end{abstract}

Key words: madness in literature - concept of madness - Till Eulenspiegel - Don Quixote - realism - German literature. 